\title{
Multiple Cranial Nerve Palsies in a Patient with Internal Carotid Artery Dissection
}

\author{
Alessia Mattioni ${ }^{\mathrm{a}}$ Maurizio Paciaroni ${ }^{\mathrm{a}}$ Paola Sarchielli $^{\mathrm{a}}$ Donatella Murasecco $^{\mathrm{a}}$ \\ Gian Piero Pelliccioli ${ }^{b}$ Paolo Calabresi ${ }^{a}$

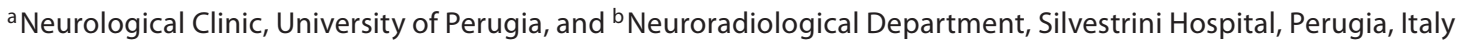

Dear Sir,

The incidence of spontaneous cervical artery dissection is approximately 5 per 100,000 per year [1]. It is estimated that internal carotid artery (ICA) dissection is responsible for $5 \%$ of all ischemic strokes and for $25 \%$ of strokes in the young $[2,3]$. With ongoing progress in neuroimaging techniques, a wider spectrum of clinical presentations regarding ICA dissection has been reported. In more than $90 \%$ of patients, ICA dissection causes carotid territory ischemia, local signs and/or symptoms on the dissection side, whereas the remaining ICA dissections are clinically asymptomatic. Cranial nerve palsy is reported in $8-16 \%$ of patients having ICA dissection [4].

Here, we report on a patient with right ICA dissection and ipsilateral multiple cranial nerve deficits (cranial nerves II, V, VII, VIII, IX, X and XII).

\section{Case Description}

A 66-year-old obese male, with a history of hypertension and past smoking, had subacute compressive moderate/ severe right temporal-parietal-occipital headache a few days after the flu, with frequent sneezing and persistent cough. A few days after headache onset, the patient experienced transient difficulties in chewing and whistling, tongue hypomobility and speech problems, particularly in the pro- nunciation of the letter ' $S$ '. The patient also described experiencing a severe dysgeusia without involvement of the motor part of cranial nerve VII and moderate right facial pain. A few days later, the patient had sudden transient (1-hour) rotatory vertigo associated with nausea and aggravated by head movements. At this time, i.e. 10 days after the first symptoms, the patient was admitted to hospital. Neurological examination showed a right syndrome of lower cranial nerve palsies with dysphonia, pharyngeal and tongue paresis (IX, X, XII), horizontal nystagmus with the rapid phase on the left (presumably due to the involvement of the cranial nerve VIII) without acoustic impairment, slight left limb sensory disturbances and diminished reflexes - especially of the lower limbs. Magnetic resonance imaging (MRI) of the brain with diffusion-weighted images was performed, and any involvement of the brainstem was excluded. Duplex ultrasound examination was normal. Electromyography and lumbar puncture excluded a neuropathy, while MRI of the pharynx and hypopharynx excluded compressive diseases. During hospitalization, the patient had a sudden, mild reduction in visual acuity in the right eye lasting for 2 days, most likely due to transient ischemic optic neuropathy. The ocular fundus was normal. Seven days after admission, because of the occur- rence of this new ocular symptom, MRI was repeated with contrast-enhanced MR angiography (MRA). MRA showed a moderate reduction in the right ICA lumen from the origin with an extension to the cranial basis (carotid canal) (fig. 1a). Up until the carotid canal, MRI with $\mathrm{T}_{1}$ and fat subtraction images revealed a hyperintense signal surrounding the narrowed lumen of the artery (fig. 1b). Subsequently, the patient has been treated with $300 \mathrm{mg}$ of aspirin per day and completely recovered from clinical symptoms after a few days. MRI performed 3 months after the onset of symptoms showed complete recanalization of the ICA. To date, 1 year later, the patient remains asymptomatic.

\section{Discussion}

Cranial nerve palsy can be present in more than $10 \%$ of patients with spontaneous dissection of the ICA $[5,6]$, and the lower cranial nerves IX-XII are most commonly affected, particularly the hypoglossal nerve. The involvement of various combinations of nerves has also been described [5, 7], but involvement of a large number of cranial nerves is very rare. The possible explanations for cranial nerve involvement are: stretching or mechanical compression by intramural hematoma of the dissected artery, interruption of the nutrient arteries supplying the cranial

\section{KARGER}

Fax +4161306 1234 E-Mail karger@karger.ch www.karger.com
(C) 2007 S. Karger AG, Basel 0014-3022/07/0582-0125\$23.50/0

Accessible online at: www.karger.com/ene
Alessia Mattioni

Neurological Clinic, University of Perugia

Silvestrini Hospital

IT-06126 Perugia (Italy)

Tel. +39075 578 4228, Fax +39075 578 4072, E-Mail alessia.mattioni@genie.it 


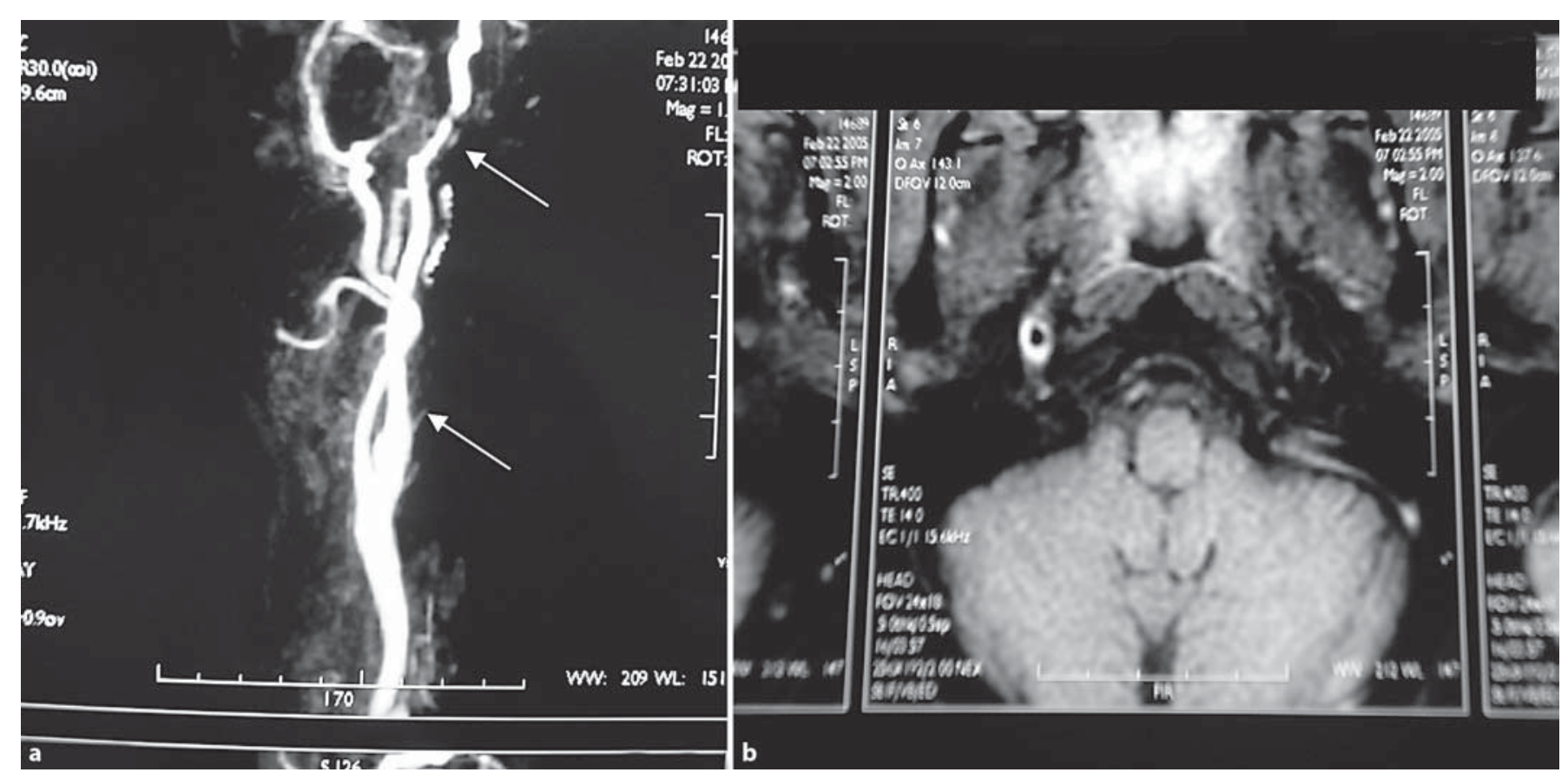

Fig. 1. Moderate reduction in the right ICA lumen from the origin with an extension to the cranial basis on MRA (a). Hyperintense signal surrounding the narrowed lumen of the artery on MRI with $\mathrm{T}_{1}$ and fat subtraction images (b).

nerves by distal embolization, and/or pressure gradient changes in collateral supply [5]. Another plausible explanation could be the anomalous origin of the nutrient vessel. Our case supports the hypothesis that lower nerve paresis is more prone to mechanical involvement, whereas higher nerve paresis is often impaired by a disturbed arterial supply.

Another important observation is that a similar clinical picture can mimic a brainstem dysfunction. In fact, the presence of lower nerve cranial involvement associated with contralateral sensory deficits can appear to be a medulla syndrome. In our patient, we repeated MRIs after ocular symptoms leading us to believe that the problem was localized in the carotid circulation. An involvement of the carotid circulation may also explain the slight transient contralateral sensory disturbances in our patient, probably due to the transient involvement of the sensory cortex.

Some cranial nerves were partially involved. Regarding the facial nerve, the chorda tympani was involved with subsequent transient severe dysgeusia. Dysgeusia due to paresis of the chorda tympani has been reported in $0.5-7.0 \%$ and may oc- cur without either another cranial nerve involvement or the involvement of the motor part of cranial nerve VII [7-9]. Dysgeusia could also be attributed to the dysfunction of the glossopharyngeal nerve [10], but most often in this case, the symptom is very slight and sometimes not reported by the patient. The anterior part of the tongue innervated from fibers arising from facial nerve prevails over the involved posterior third of the tongue.

More difficult to explain is the probable involvement of the cranial nerve VIII. In our case, the symptomatology was typical with vertigo and nystagmus. A possible anatomical variant (e.g., persistence of embryonic anastomotic vessels between the internal carotid artery and the basilar arterial system) occasionally persist into adult life [11-13]. This variant could also partially explain the involvement of the cranial nerve $\mathrm{V}$, even if facial pain may occur in $34-53 \%$ of all patients with ICA dissection for a referred pain due to dissection itself $[8,14]$.

In conclusion, in ICA dissection patients, multiple involvement of ipsilateral cranial nerves can be observed. Multiple cranial nerve palsy associated with contra- lateral neurological deficits may cause false clinical localization of the lesion, leading one to hypothesize that the vertebrobasilar circulation is involved, whereas in reality, the pathological process is actually located in the ICA circulation.

\section{References}

1 Schievink WI: Spontaneous dissection of the carotid and vertebral arteries. N Engl J Med 2001;344:899-906.

2 Ducrocq X, Lacour JC, Debouverie M, Bracard S, Girard F, Weber M: Accidents vasculaires cérébraux ischémiques du sujet jeune: étude prospective de 296 patients âgés de 16 à 45 ans. Rev Neurol 1999;155:575-582.

3 Guillon B, Levy C, Bousser MG: Internal carotid artery dissection: an update. J Neurol Sci 1998;153:146-158.

4 Baumgartner RW, Bogousslavsky J: Clinical manifestations of carotid dissection; in Baumgartner RW, Bogousslasvky J, Caso V, Paciaroni M (eds): Handbook on Cerebral Artery Dissection. Front Neurol Neurosci. Basel, Karger, 2005, vol 20, pp 70-76.

5 Mokri B, Silbert P, Schievink WI, Piepgras DG: Cranial nerve palsy in spontaneous dissection of the extracranial internal carotid artery. Neurology 1996;46:356-359. 
6 Schievink WI, Mokri B, Garrity JA, Nichols DA, Piepgras DG: Ocular motor nerve palsies in spontaneous dissections of the cervical internal carotid artery. Neurology 1993; 43:1938-1941.

7 Baumgartner RW, Arnold M, Baumgartner I, et al: Carotid dissection with and without ischemic events: local symptoms and cerebral artery findings. Neurology 2001;57: 827-832.

8 Silbert PL, Mokri B, Schievink WI: Headache and neck pain in spontaneous internal carotid and vertebral artery dissections. Neurology 1995;45:1517-1522.

9 Schievink WI: A surgeon with a nasty taste in his mouth. Lancet 1997;350:260.
10 Taillibert S, Bazin B, Pierrot-Deseilligny C: Dysgeusia resulting from internal carotid dissection. A limited glossopharyngeal nerve palsy. J Neurol Neurosurg Psychiatry 1998;64:691-692.

11 Hui MS, Choi WM, Liu HM, Huang KM, Perng HL, Chen LK: Anomalous origin of the posterior inferior cerebellar artery from the pre-cavernous portion of the internal carotid artery; a primitive trigeminal artery variant. Eur J Radiol 1994;19:10-13.
12 Ito J, Takeda N, Szuki Y, Tekeuchi S, Osugi S, Yoshida Y: Anomalous origin of the anterior inferior cerebellar arteries from the internal carotid artery. Neuroradiology 1980;19:105109.

13 Katoh M, Kamiyama H, Kobayashi N, Makino K, Takano K, Tokumitsu N, Takamura H: Severe stenosis of the internal carotid artery presenting as loss of consciousness due to the presence of a primitive hypoglossal artery: a case report. Surg Neurol 1999;51:310-312.

14 Biousse V, D’Anglejan-Chatillon J, Massiou $\mathrm{H}$, Bousser MG: Head pain in non-traumatic carotid artery dissection: a series of 65 patients. Cephalalgia 1994;14:33-36. 